\title{
Carlos Chagas Filho e a doença de Chagas. Alguns traços à luz de confidências e inconfidências
}

\author{
João Carlos Pinto Dias*
}

Aos 17 de fevereiro de 2000, faleceu no Rio de Janeiro Carlos Chagas Filho. Era o segundo filho de Carlos Ribeiro Justiniano das Chagas, o imortal descobridor da Tripanossomíase Americana. Quase que em seguida, a 20 de março pp. reuniram-se, também, no Rio representantes dos 7 Países do Cone Sul que desde 1991 houveram por bem combater conjuntamente a doença, numa iniciativa ímpar e bem sucedida. Presentes a OPS, a OMS, a FUNASA e a SUCEN, no âmbito de Manguinhos, naturalmente, Chagas Filho foi relembrado por todos e reverenciado com apreço e saudade. Ao ensejo, secundando a emoção e as palavras belíssimas do Prof. José Rodrigues Coura, vieram à baila estas "inconfidências" que a Revista da SBMT achou por bem acolher.

Foi uma figura simples e amena, grande amigo e referência humana para todos que o conheceram. Certa vez, em Belo Horizonte, terminada uma conferência magistral na Faculdade, presentes o Governador e Autoridades, chamou-me a um canto e propôs sairmos de mansinho para ir à minha casa e vermos o que haveria na geladeira. Queria falar-me de seu Pai, fazendo-o longa e carinhosamente durante

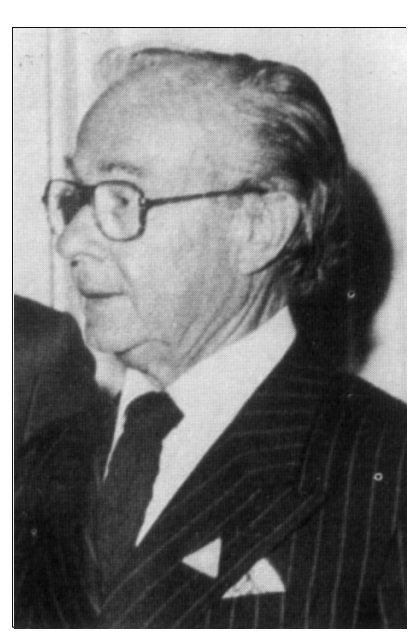

Carlos Chagas Filho. 1910-2000 (Acervo JCP Dias). entender e proclamar o contexto de miséria e injustiças onde medrava a doença. Chagas Filho, sempre que podia, falava de Carlos Chagas, nunca abstraindo suas lutas, posturas e emoções. Punha-se a si mesmo na história, que viveu intensamente em Álvaro Chaves, no casarão da rua Paissandu e em Manguinhos. Aliás, Chagas Filho nasceu nos alvores da descoberta (Rio, 1910), logo dando-se conta de ter um pai muito afetuoso, um tremendo trabalhador, um ser enigmático que vivia um mundo cheio de mistérios e que atraía gente importantíssima ao seu convívio, até reis, ministros e presidentes. Em tal contexto cresceram, ele, o "Chaguinhas," e Evandro. Da fräulein Elza Dinges, a governanta que Ihes ensinou o alemão, aprenderam também o francês e iniciaram-se no inglês. Em tudo, como sombra e amparo, D. Íris foi a mãe exemplar, a marcar profundamente nos dois meninos a delicadeza, a temperança, a admiração e o amor pelo esposo. Evandro, o querido irmão mais velho, foi um ardente e brilhante companheiro, "cujo espírito sempre me acompanhou". Por isto, a ambos consagrou carinhosamente seu livro "Meu Pai". Carlos Chagas Filho foi biofísico de renome internacional, o omelete improvisado por minha filha Ruth. De outra feita, impactado com os avanços da pesquisa básica em Caxambu, confidenciou-me que seria muito importante que o controle e o tratamento da doença de Chagas não fossem descuidados. Desta conversa, em 1978, ocorreuIhe discutir os aspectos sociais da doença de Chagas num congresso internacional que planejava montar para o ano seguinte. Lembravase do pai, em memoráveis conferências, a homem de letras, pai amantíssimo de quatro lindas moças e o esposo devotado da inseparável D. Anna. Formou-se em Medicina em 1934, na mesma "Praia Vermelha", excelente aluno, vivendo com seu pai e Evandro as mesmas paisagens no Flamengo, na Escola e no Instituto. Em 1931, esteve com Emmanuel Dias em Lassance, ali revendo pacientes e cenários históricos. Não se dedicou, entretanto à doença de Chagas. Evandro já o fazia, inclusive com tese doutoral

\footnotetext{
* Pesquisador Titular da Fundação Oswaldo Cruz (Centro de Pesquisas René Rachou). e-mail: jcpdias@cpqrr.fiocruz.br
} 
em 1934 sobre "Aspectos Eletrocardiográficos". $\mathrm{Na}$ verdade, confidenciava, o nome lhe era muito caro mas também muito lhe pesava. Além do mais, a influência de Miguel Couto e o curso complementar de aplicação, no IOC, o levaram para a Fisiologia, embrião do Instituto de Biofísica que viria a fundar em 1945. Certamente também Carlos Chagas o entusiasmou, apaixonado que era pelos aspectos fisiopatogênicos da nosologia brasileira, um de seus textos mais brilhantes ${ }^{2}$. Desta encruzilhada (um dilema?), Chagas Filho saiu-se à mineira, alçando vôo próprio na Fisiologia e assumindo um compromisso de jamais descuidarse da memória e dos ideais de seu ídolo maior. Aqui, basicamente, um ideário fundamental, a traduzir do pai a mesma perspectiva de "uma grande sciencia, de uma grande e bella sciencia, que se faz arte na defesa da vida"4. Aos 27 anos tornava-se o mais jovem catedrático da Faculdade. Saiu de Manguinhos em 1937, dizia, para levar sua colaboração à Praia Vermelha, ali ingressando após brilhante concurso. Teria sido um acordo com Evandro, então dinâmico diretor do Serviço de Grandes Endemias do IOC? Ficariam independentes, os dois irmãos, nos espaços mais nobres ocupados por Carlos Chagas, a zelar-lhe os sonhos, a seguir-lhe as pegadas? Perdendo o pai em 1934, em 1940 sofreu novo e tremendo impacto com a morte de Evandro, em um acidente aéreo, quedando-se desde então, como o definitivo depositário da memória de Chagas. Enorme encargo sobre um espírito ainda tão jovem e já tão atento, sobre um jovem inteligente, saudoso e abalado, sobre um romântico e religioso personagem que ouvira de seu pai o que este apreendera de Oswaldo: "não esmorecer para não desmerecer". Chagas Filho se determinara e fora determinado a reviver Carlos Chagas nas dimensões maiores do homem, do cidadão e do cientista. Teria que servir ao seu País, comprometerse com ele e com seu povo, tinha pela frente uma universidade a construir, tinha que mostrar e combater a doença de Chagas, viveria para sempre uma imensa saudade. Lembrava-se a cada momento de seu pai. Contou-o aguerrido, na disputa com Kraus, brilhante e irritado nas disputas da Academia, entristecido depois, quiçá desapontado com a fraqueza de alguns "amigos". Desconhecia o Nobel perdido, explicando o silêncio de Carlos Chagas como uma característica dos fortes e dos bravos, muito acima e além das disputas comezinhas e dos pequeninos interesses. Relembrou Chagas em dezenas de artigos e capítulos, retratou-o ternamente no "Meu Pai"7.
Na Biofísica e na Universidade, postou-se a criar uma grande escola e a universalizar a ciência. Com cerca de duzentos trabalhos sobre eletrofisiologia, abriu definitivamente o Brasil para os campos correlatos, fez emergir a pós graduação, deixou centenas de discípulos. Participou com Paulo de Assis Ribeiro na criação do CNPq, em 1951, sob inspiração do Conselho de Pesquisas da França, entendendo a importância da ciência na conformação social e ética do País ${ }^{8}$. Integrou quadros da UNESCO, da OMS, e diversos comitês e colegiados nacionais e internacionais de ensino e pesquisa. Presidiu por quase vinte anos a Academia Pontifícia de Ciências do Vaticano. Ao longo, empenhou-se aguerridamente pela $\mathrm{Paz}$, pelo desarmamento atômico, pela preservação do meio ambiente, pela humanização da ciência, pela reabilitação de Galileu. Recebeu títulos e honrarias por toda parte, sem jamais perder sua simplicidade e sua serenidade, ou distanciar-se das pessoas. Em particular, sempre se deixou cercar pelos moços, também confidenciando que se sentia impelido a fazer ponte entre Carlos Chagas e as novas gerações. Já de Lassance, dizia, ali veio a descobrir a vida e o sofrimento dos pobres ${ }^{8}$. Ao tratar o assunto de seu pai, Chagas Filho se transfigurava, assumindo um brilho intenso nos olhos e uma expressão de adoração e ternura. Fez centenas de conferências, escreveu dezenas de artigos, capítulos, um lindo livro. Viu Chagas sob diversos ângulos, do cientista ao homemcidadão, do professor ao político, do pai ao amigo $^{567}$. Viu-o lutador incansável, um caçador, um fumante inveterado. Descreveu-lhe a trajetória acadêmica, suas lutas na juventude, os sonhos todos. Pintou-Ihe delicadamente cenários, influências, emoções. Dentre estas, a tremenda ansiedade daquela interminável viagem entre Lassance e o Rio, em dezembro de 1908, para encontrar-se com Oswaldo e definir, de vez, o seu tripanosoma. Ou então, três meses depois, ainda mais emocionado, ao regressar a Lassance já sabedor que Berenice ali o esperava. Lembrou os amigos e os companheiros de Chagas, seus discípulos mais diletos, também os desafetos e os invejosos. Traduziu de novo e deu novas cores à adoração que Chagas devotava a Oswaldo. Recebeu de D. Íris as lembranças mais queridas, destinando-as com amor e despojamento à Casa de Oswaldo Cruz, porque simplesmente pertenciam ao país, à humanidade, não a ele.

Doença de Chagas. Sem dedicar-se diretamente a ela, fez muito pela doença de Chagas, especialmente a partir dos anos 50 , quando já 
assumira total maturidade e liderança científica. Lembro-me de visitá-lo, ainda menino, muitas vezes, com meu pai, Emmanuel Dias. Mais que amigos,

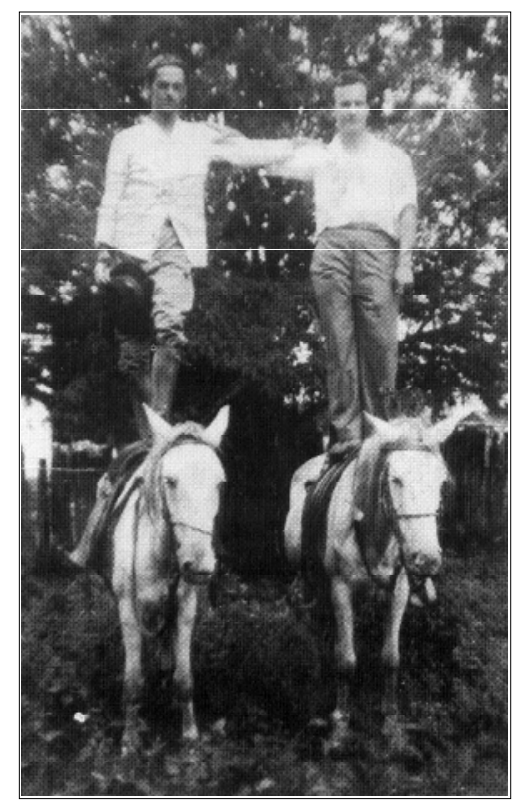

Carlos Chagas Filho (E) e Emmanuel Dias em Lassance, 1931 (Acervo JCP Dias).

irmãos de juventude, sócios na Faculdade de um velho Chevrolet, abraçavam-se alegremente e, de imediato, o "Chaguinhas" disparava perguntas sem fim. Muito cedo se apercebeu que de Bambuí estavam sendo descortinados e clareados vários paradigmas que Carlos Chagas ardorosamente defendera. Vislumbrando um tempo novo, o Chaguinhas queria saber do controle da doença. Velhos camaradas, sempre havia o que lembrar (gostosíssimas gargalhadas), mas também o que sonhar. Chagas Filho, um pouquinho mais novo, inflamava ainda mais as inquietudes do outro, entusiasmando-o ao limite, sempre procurando ajudar. Apoiou concretamente Bambuí, viabilizou contatos muito importantes. Amadureceram juntos dois projetos ambiciosos à época, logo após uma ampla revisão por Dias da doença de Chagas nas Américas e a publicação de um Atlas Internacional sobre a tripanossomíase ${ }^{11}$ : uma exposição internacional (Palais de la Dècouverte, Paris, 1955), e um congresso internacional (Rio, 1959). Era necessário aclarar, de vez, o significado da doença, divulgá-la universalmente, ajuntar pessoas e instituições. Os objetivos finais seriam o controle da endemia (equacionado em Bambuí) e o desenvolvimento de uma cultura científica que a tripanossomíase poderia proporcionar à academia latino-americana. Clemente Mariani, Mário Pinotti, Álvaro Alberto, Gustavo Capanema, Juscelino Kubitcheck, Milton Campos, Carlos Drumond de Andrade, Clóvis Salgado e outras grandes personalidades foram companheiros que se envolveram em tudo isto, viabilizando projetos, arrancando verbas, entusiasmando-se também. André Leveillé foi trazido ao Brasil, visitou Bambuí, levaram barbeiros e uma cafua inteira a Paris, um sucesso. Deste evento, uma decepção, também uma lição, que Chagas Filho mais tarde relembrou: "Sem dúvida, a exposição no "Palais de la Dècouverte" deu à doença de Chagas uma nova perspectiva no cenário mundial... Um fato que cito apenas aqui para constatar a imaturidade brasileira em relação a certos assuntos, é que esta Exposição - que colocou Chagas ao nível dos maiores expoentes da ciência mundial - teve ressonância praticamente nula no cenário brasileiro..." O O Congresso reuniu em Manguinhos centenas de investigadores brasileiros e estrangeiros, prenúncio, certamente, de uma arrancada, que se repetiria anos depois. Ali se integrou de uma vez a comunidade dos chagólogos, discutiram-se todos os aspectos da doença, conclamou-se definitivamente pelo controle, agora respaldado pelos dados de Dias, Pedreira de Freitas e Amador Neghme. Paralelamente ao congresso emergiu uma "Bibliografia sobre Doença de Chagas", utilíssima para todo o Continente, produzida pelo $\mathrm{CNPq}^{1}$. Mais tarde, em 1979, Carlos Chagas Filho protagonizou um outro congresso internacional, para comemorar os 100 anos de nascimento de seu pai. Retomava a idéia inicial de Chagas, envolvendo cientistas e homens de decisão ao Hotel Glória, por quatro dias, para atualizar-se no conhecimento da doença e abrir, de vez, a perspectiva do seu controle. Realmente, assim se fez, aliás, deu certo. Levou-se o Presidente da República, João Batista Figueiredo, à sessão inaugural do Congresso, onde as falas e uma exposição no "hall" de entrada do centro de convenções apelavam para o sentido social da doença e indicavam a viabilidade do seu controle. Contam J.R. Coura e A.R. Prata que tudo foi intermediado pelo então Ministro da Saúde, Mário Augusto de Castro Lima, que os levou com Chagas Filho ao Presidente alguns meses antes do congresso. No Planalto, em poucos minutos 


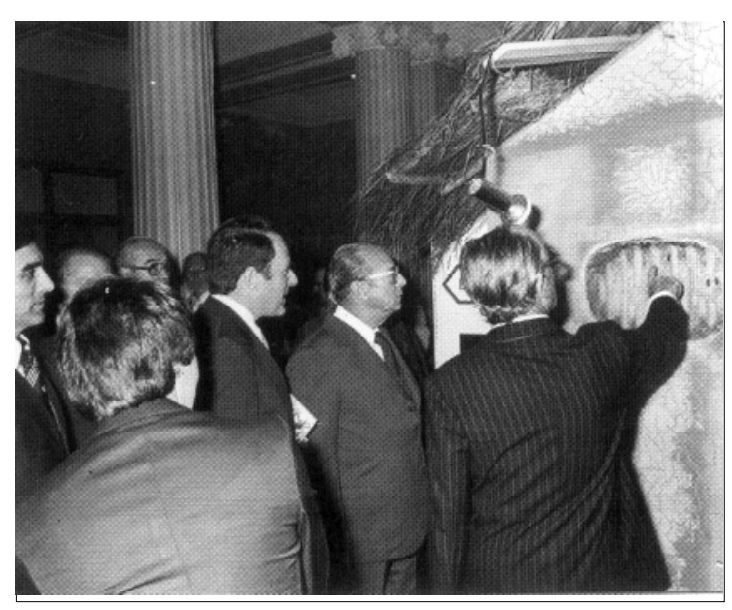

Carlos Chagas Filho e o presidente João Figueiredo na Exposição de Abertura do Congresso Internacional sobre Doença de Chagas, Rio de janeiro, 1979. (Acervo JCP Dias).

empenhou-se o recurso financeiro para o evento e comprometeu-se a agenda do Presidente. A comunidade científica reviveria, em julho de 1979, a célebre reunião da Academia Nacional de Medicina, 68 anos antes, onde Carlos Chagas foi ouvido por um outro presidente, Hermes da Fonseca, encerrando sua brilhante fala com o apelo: "Entre nós, a iniciativa de medidas sanitárias justifica-se, sem dúvida, em considerações bem mais elevadas: é o futuro de um grande povo que se deverá zelar; são deveres de humanidade e de patriotismo que devem actuar no espirito progressista dos homens de estado..." congresso de 79 reuniu centenas de pesquisadores e daí emergiu, concretamente, o impulso que faltava para a priorização do controle da doença de Chagas no Brasil, que viria a consolidar-se em $1982^{12}$. Deste congresso também nasceu uma iniciativa espontânea da comunidade científica, o "Comitê Científico Internacional para o Controle da Doença de Chagas", que atuou durante 9 anos sob a presidência de Cecilio Romaña, Pilar Alderette e J. Rodrigues Coura, sem dúvida aproximando grupos de trabalho e facilitando, para a década de 90 , a formulação bem sucedida da "Iniciativa do Cone Sul", hoje seguida de iniciativas semelhantes no Pacto Andino e na América Central ${ }^{12}$. Em tudo isto, silenciosa e despretensiosamente, o dedo, a inspiração e a clarividência de Carlos Chagas Filho, que José Rodrigues Coura interpretou como "uma lucidez que nos ilumina e uma juventude que nos inspira"10. Depreende-se que a participação de
Chagas Filho no tema da doença de Chagas foi enorme e altamente profícua, ainda que não necessariamente se envolvesse com ela na bancada ou no hospital. De sua liderança, de seu prestígio, de seu esforço consciente e continuado, indubitavelmente se beneficiaram os pesquisadores, a ciência e a população envolvidos com o Trypanosoma cruzi. Como analisado por Morel, atuações indiretas como as de Carlos Chagas Filho se fizeram altamente benéficas no encaminhamento do problema, pelo menos em três níveis: a) o de sensibilizar a opinião pública e da Academia; b) no influenciar diretamente o governo, e, c) no estimular a formação de lideranças e de tomadas de decisão ${ }^{13}$. Como síntese de tudo isto, suas palavras de inauguração do Curso sobre Doença de Chagas em Belo Horizonte, 1964, espelham os anseios, a coragem e a determinação de seu espírito frente à esquizotripanose:

"Ao terminar... faço votos para que esta conferência alcance a dupla finalidade que todos desejamos. Sirva de um lado para aumentar a capacidade técnica e científica dos que estudam a doença de Chagas, pelo intercâmbio de idéias e pelo desenrolar de problemas comuns, mas sirva também para focalizar a atenção de nossos organismos federais e estaduais, e de nossa sociedade, mais uma vez, para o caráter prioritário que as campanhas sanitárias para o extermínio da doença de Chagas devem assumir, no conjunto de medidas saneadoras que constituem o processo autêntico de reformas sociais no qual o Brasil acaba de entrar'6.

Chagas Filho viveu intensamente, honrando seu Pai e seu País. Viveu dignamente o nome que carregava, viveu o dilema natural disto conseqüente, entendeu que "a humanização do meu ser era tão importante quanto a formação técnica ou científica a que deveria me dedicar's. Numa de suas últimas alocuções sobre seu pai, em 1999, retrata-se de maneira fidelíssima ao referir-se a Carlos Chagas: "Pessoalmente era um homem simples. Amigo de seus amigos e a eles profundamente dedicado... Acho que podese dizer que Chagas era essencialmente um brasileiro pelo amor que dedicou ao seu país e pelo interesse de procurar o bem estar de seus concidadãos...".

Morreu sereno e altivo, lúcido e atuante, até o fim, como seu pai. Encarnou o lobo ferido, de Vigny, em sua batalha, nunca reclamando, apenas lutando:

"Seul le silence est grand...Toute le reste est faiblesse".

Belo Horizonte, abril de 2.000. 


\section{REFERÊNCIAS BIBLIOGRÁFICAS}

1. Conselho Nacional de Desenvolvimento Científico e Tecnológico (CNPq). Doença de Chagas (bibliografia brasileira e internacional). CNPq/Instituto Brasileiro de Bibliografia e Documentação (ed), Rio de Janeiro, 1958.

2. Chagas CRJ. Processos patogênicos da tripanosomíase americana. Memórias do Instituto Oswaldo Cruz, Rio de Janeiro, p.5-36, 1916.

3. Chagas CRJ. Moléstia de Carlos Chagas. Segunda Conferência realisada na Academia Nacional de Medicina em Agosto de 1911. In: Prata AR (org) Carlos Chagas. Coletânea de Trabalhos Científicos. Editora Universidade de Brasília, Brasília, p. 167-192, 1981.

4. Chagas CRJ. Lição de abertura dos cursos da Faculdade de Medicina do Rio de Janeiro - 1928. In: Prata AR (org) Carlos Chagas. Coletânea de trabalhos científicos. Editora Universidade de Brasília, Brasília, p. 861-883, 1981.

5. Chagas Filho C. Histórico sobre doença de Chagas. In: Cançado JR (ed) Doença de Chagas. Imprensa Oficial, Belo Horizonte, p. 5-21, 1968.

6. Chagas Filho C. Carlos Chagas e seus colaboradores. In: Cançado JR, Chuster M (org) Cardiopatia chagásica. Fundação Carlos Chagas, Belo Horizonte, p. IXX-XXIII, 1984.

7. Chagas Filho C. Meu Pai. Casa de Oswaldo Cruz, Rio de Janeiro, 1993.
8. Chagas Filho C. Discurso de agradecimento ao receber a Medalha Oswaldo Cruz, no Instituto Oswaldo Cruz, em $1^{\circ}$ de outubro de 1999. Notas pessoais de João Carlos Pinto Dias, Rio de Janeiro, 1ำ de outubro, 1999.

9. Chagas Filho C. Lembranças de meu pai. Conferência de abertura do Congresso Internacional sobre doença de Chagas, Academia Mineira de Medicina, Belo Horizonte, 22 de novembro, 1999. (Lida por João Carlos Pinto Dias a pedido do autor, já enfermo). Em publicação pela Academia Mineira de Medicina, 1999.

10. Coura JR. Palavras a Carlos Chagas Filho, na outorga da Medalha Oswaldo Cruz, em 1ำ de outubro, 1999. Notas pessoais de João Carlos Pinto Dias, Rio de Janeiro, $1^{\circ}$ de outubro de 1999.

11. Dias E. Chagas-Krankheit. In: Welt-Senchen Atlas, Verlag, Hamburg, p. 135-140, 1954.

12. Dias JCP, Schofield CJ. The evolution of Chagas Disease (American Trypanosomiasis) Control after 90 years since Chagas discovery. Memórias do Instituto Oswaldo Cruz 94 (supl I): 103-123, 1999.

13. Morel CM. Chagas Disease, from discovery to Control. Memórias do Instituto Oswaldo Cruz 94 (supl I): 3-16, 1999. 